\title{
Investigation of Ovarian Follicular Waves and Major Hormonal Profile in Red Chittagong Cattle
}

\author{
Saiful Islam¹, Md. Ahsanul Kabir², Md. Faizul Hossain Miraz², Effat Jahan Tamanna1, \\ Satya Ranjan Sarker ${ }^{1}$, Zinia Islam¹, S. M. Jahangir Hossain ${ }^{2}$, Sharif Hossain ${ }^{1 *}$, Gautam Kumar Deb ${ }^{2 *}$ \\ ${ }^{1}$ Department of Biotechnology and Genetic Engineering, Jahangirnagar University, Dhaka, Bangladesh \\ ${ }^{2}$ Biotechnology Division, Bangladesh Livestock Research Institute, Savar, Dhaka, Bangladesh \\ Email: *sharifhossain@juniv.edu, *debgk2003@yahoo.com
}

How to cite this paper: Islam, S., Kabir, Md.A., Miraz, Md.F.H., Tamanna, E.J., Sarker, S.R., Islam, Z., Hossain, S.M.J., Hossain, S. and Deb, G.K. (2020) Investigation of Ovarian Follicular Waves and Major Hormonal Profile in Red Chittagong Cattle. Advances in Bioscience and Biotechnology, 11, 7-21.

https://doi.org/10.4236/abb.2020.112002

Received: January 8, 2020

Accepted: February 15, 2020

Published: February 18, 2020

Copyright $\odot 2020$ by author(s) and Scientific Research Publishing Inc. This work is licensed under the Creative Commons Attribution International License (CC BY 4.0).

http://creativecommons.org/licenses/by/4.0/

\begin{abstract}
Red Chittagong Cattle (RCC) is one of the renowned varieties of cattle which is indigenous and most potential type of domestic animal genetic resource in Bangladesh with distinct phenotypic characteristics. Reproductive management might be a process for multiplying this cattle variety. Therefore, the goals of this study were to characterize the follicular waves of RCC and to determine the Progesterone $\left(\mathrm{P}_{4}\right)$, Follicle Stimulating Hormone (FSH) and Luteinizing Hormone ( $\mathrm{LH})$ profile during three consecutive estrus cycle. Follicular wave emergence (Day 0) was identified using trans-vaginal ultrasound technique and follicular growth was then monitored from Day 0 to Day 23 during three consecutive estrus cycle and blood samples were collected. After measuring the growth and diameter of the follicles, hormonal assays of collected blood samples were performed using Enzyme Linked Immunosorbent Assay (ELISA). We found that, both RCC cows and heifers showed two waves inter-ovulatory intervals. The length of inter-ovulatory intervals and the diameter of the ovulatory follicle of RCC cows and heifers were slightly different from each other. The identification of the dominant follicle was confirmed from the start of its deviation from other subordinate follicles till it reached to the maximum diameter and identified as dominant follicle which increases linearly for approximately six days (growing phase). This dominant follicle is remained approximately same size for five days (static phase), and then begins to regress (regressing phase) decreasing the antral diameter. The follicular waves are first detectable as $4-5 \mathrm{~mm}$ follicles approximately at day 0 and day 10 both for RCC cows and heifers which showed two waves inter-ovulatory intervals. The circulating varied concentrations of LH, FSH and $\mathrm{P}_{4}$ were determined using ELISA in case of both cows and heifers and the
\end{abstract}


concentration curves followed the similar pattern of change during the estrus cycle. Hence, the knowledge about ovarian follicular waves will create a base line for reproductive management of RCC as well as to allow reproductive biotechnologies to improve and multiply this cattle variety.

\section{Keywords}

Red Chittagong Cattle, Ovarian Follicles, Progesterone, Follicle Stimulating Hormone, Luteinizing Hormone, ELISA

\section{Introduction}

Red Chittagong Cattle (RCC) is native cattle available in Bangladesh. Among all other indigenous cattle varieties, RCC is one of the promising varieties of cattle discovered in 1990s and has made themselves attractive for their distinct phenotypic characteristics and adaptable capabilities to the hot humid climatic environment. It has high resistant to diseases especially under rural production systems, requires lower input support than crossbreds and produces milk and beef of high quality [1]. Moreover, it shows more reproductive potentiality than others indigenous and crossbred in tropical climate condition. However, due to crossbreeding this potential variety is in endanger condition at present. Therefore, reproductive management might be a process for multiplying this cattle variety. The knowledge about ovarian follicular waves will create a baseline for proper reproductive management of RCC.

Ovarian follicular growth in cows follows a wave-like pattern. During a wave of follicular dynamic the synchronous growth of a group of follicles occurs, one of which becomes dominant and acquires the largest diameter suppressing the subordinate smaller follicles [2]. The ultrasonic examination of ovarian follicles reveals that the most estrus cycle in cows has two or three follicular waves [3]. It is evident that the identification of dominant follicle was reported from the start of its deviation from other subordinate follicles till reached the maximum diameter and identified as dominant follicle, increased linearly for approximately six days (growing phase), remained approximately same size for five days (static phase), and then began to regress (regressing phase) decreasing the antral diameter. The follicular waves are first detectable as $4-5 \mathrm{~mm}$ follicles approximately day 0 and day 10 for two waves and day 0,9 and 16 for three waves inter ovulatory intervals [4]. Consequently, to examine the domestic animal reproduction in pregnant sheep [5], ultrasonography was utilized in different fields of reproductive research, including follicular elements, ovulation, corpus luteum development, uterine checking, and fetal imaging [6]. Nonetheless, it is hard to follow the elements of a solitary follicle in the ovary of a live animal. Ultrasonography has been utilized to watch follicular development in the ovary of domestic animals. These examinations uncovered an intermittent rush of advancement in every estrus cycle, amid which a gathering of enlisted follicles grew. These 
formative waves comprised of the enrollment of developing follicles, determination of predominant follicles, and ovulation. The influxes of follicular improvement are started by gonadotropin. The estrus of the cow is basically controlled by hormones delivered by the central nervous system, pituitary and ovary. Gonadotrophic releasing hormone ( $\mathrm{GnRH})$, emitted by the central nervous system, invigorates the foremost pituitary to emit two gonadotrophic hormones such as Follicle Stimulating Hormone (FSH) and Luteinizing Hormone (LH). Both hormones control ovarian capacity. FSH starts development of follicles, and LH instigates ovulation and luteinisation of granulosa and thecal cells [7]. Another significant hormone secreted by the Corpus Luteum (CL) is progesterone $\left(\mathrm{P}_{4}\right)$ which maintained the pregnancy of cattle. Proper identification of the follicular wave of RCC and clarification of the association of circulating LH, FSH and $\mathrm{P}_{4}$ concentration during the estrus cycle will ensure enhanced reproduction which is required for the spread of generation in any species. Since, the RCC of Bangladesh is a promising kind of cattle genotype having some potential reproductive capacities, reproduction of this variety is the starting the following endeavors for yields like meat, milk and so forth. Thus, the aims of this study were to characterize the ovarian follicular waves and to determine the circulating $\mathrm{LH}$, FSH and $\mathrm{P}_{4}$.

\section{Materials and Methods}

\subsection{Animals and Location}

The study was carried out at the department of Biotechnology and Genetic Engineering, Jahangirnagar Univesity, Savar, Dhaka; Biotechnology Division of Bangladesh Livestock Research Institute (BLRI) and at the cattle research herd of BLRI from October, 2018 to March, 2019. RCC cows $(n=5)$ and heifers $(n=5)$, body weight and ages of $200 \mathrm{~kg}, 150 \mathrm{~kg}$ and 4 years and 2 years old respectively were used in this experiment. The overall body condition was sound and all animals were in regular estrus. The animals were reared in semi-intensive system where they grazed daily $6 \mathrm{hr}$ and supplementation was done with concentrates ( $1 \%$ of body weight) in the morning and evening. Water and mineral licks were provided ad libitum. The animal protocols used were approved by the concerned authority of BLRI.

\subsection{Experimental Design}

\subsubsection{Follicular and Luteal Dynamic Observation}

The reproductive status of the selected animals was confirmed by rectal palpation and trans-vaginal ultrasonography. Ovarian follicular dynamics and trans-vaginal ultrasonography was carried out using a real time B mode ultrasound scanner named HS-2200V produced by Honda Electronics Co., LTD and equipped with a $7.5 \mathrm{MHz}$ probe. Ultrasonography was performed on non-pregnant pubertal cattle and those that were expected to be in estrus. The ovaries were scanned for presence of the corpus luteum and/or follicles. Ultra- 
sonograpic examination was performed daily during three successive natural estrus cycle, starting on Day 17 of the previous cycle and ending on day 4 of the subsequent cycle. Each examination was performed while the animal was in chute. The reproductive tract was not palpated prior to ultrasonography. The following routine was maintained for each examination. All equipment and hands were properly cleaned with alcohol and long gloves were put in hands. The ultrasound examination was done by a well-trained technician. Feces were removed from the rectum. Left hand was inserted into the rectum and grasped the ovary very gently. The vaginal-transducer was inserted into the rectum. Each ovary was scanned several times and in more than one plane, scanning first in a lateral to medial direction and then in a medial to lateral direction. Ovaries were scanned in a second direction like dorso-ventral, intermediate oblique or, in some cases cranio-caudal.

\subsubsection{Blood Collection and Processing for Major Hormonal Assay}

The subject animals were physically restrained in a service chute and $3 \mathrm{ml}$ of blood collected from the Jugular vein into vacutainer contained clot activator (BD Vacutainer sodium heparin, Franklin Lakes USA) after swabbing the jugular vein area with a cotton swab soaked in surgical spirit. The clot activator red headed tubes were labelled with the animal identification number and date of collection. Cattle were bled everyday throughout the study where a period starting with the regression of the corpus luteum (monitored by ultrasonography) is ended at noon on day 2 of the subsequent cycle [3]. Blood samples for progesterone, follicular stimulating hormone (FSH) and Luteinizing hormone (LH) level analysis $(3 \mathrm{ml}$ ) were collected from the jugular vein using $10 \mathrm{ml}$ syringe into $6 \mathrm{ml}$ blood collection tube with clot activators. The collection tubes containing the blood samples were then kept in ice box for rapid clotting for 15 minutes. Then the Blood samples were centrifuged at $4^{\circ} \mathrm{C}$ temperature in $3000 \mathrm{rpm}$ for 10 minute and the extracted serum was stored at $-20^{\circ} \mathrm{C}$ until hormonal analysis by ELISA.

\subsection{Image Analysis for Measuring Follicular and Luteal Growth}

Each ultrasound examination was recorded on videotape and the images were saved for analysis. All documents were collected as cows and heifers wise according to their respective days. The videotape was consequently reviewed on the screen of the scanner and a diagram depicting the relative location of follicles and the corpus luteum for each ovary. Follicles were measured as to follow the pattern of growth and regression of individual follicles during the entire estrus cycle. All ultrasound examinations and review of videotapes were performed by an operator who was an expert of ultrasound scanners [3].

\subsection{Hormonal Assays}

Circulating concentrations of $\mathrm{P}_{4}, \mathrm{FSH}$ and $\mathrm{LH}$ were determined by ELISA, using commercial ELISA kit provided by the Monobind Inc., Lake Forest, CA 92630, 
USA at the SAARC Regional Leading Diagnostic Laboratory for PPR of Bangladesh Livestock Research Institute (BLRI), following procedures provided by the manufacturer. Assay sensitivity was $0.5 \mathrm{mIU} / \mathrm{ml}, 0.4 \mathrm{mIU} / \mathrm{ml}$ and $0.105 \mathrm{ng} / \mathrm{ml}$ for $\mathrm{LH}, \mathrm{FSH}$ and $\mathrm{P}_{4}$, respectively. Quality control was performed according to the manufacturer's instructions.

\subsection{Statistical Analysis}

The data for characteristics of follicular waves and dominant follicle (DF) as well as growth features of CL were processed using different methods [8] [9]. Briefly, the length of the estrus cycle was determined as the interval between ovulations. Individual follicles were identified and followed when their size reached $\geq 2 \mathrm{~mm}$ in diameter. The individual follicular growth was scored over the days. The day when follicles developed to $\geq 2 \mathrm{~mm}$ was defined as the day of wave emergence. The follicle deviation is defined as the beginning of the differential change in growth rate between the largest follicles subsequent to wave emergence and is considered to be a key component of follicle selection according to the method previously described [10]. The growth rate, maximum diameter and the day of onset of atresia were analyzed. The period from the first emergence of follicles having measurable diameters, to the last day when the maximum diameter was recorded and was defined as the growing phase, and the period from the day when the maximum diameter declined, to the day when the last measurable size was observed was defined as the regressing phase. The DF was defined as the largest follicle in a diameter of $>8 \mathrm{~mm}$ and being at least $2 \mathrm{~mm}$ larger than other follicles. The day of ovulation was decided to be the day when the ovulation was confirmed by ultrasonography; ovulation was defined as the disappearance of a dominant follicle, followed by the development of a CL previously occupied by the ovulatory dominant follicle. The estrus cycle periods were defined by the number of days when the $\mathrm{P}_{4}$ level declined from $<2$ to $\leq 1 \mathrm{ng} / \mathrm{ml}$ in proestrus, declined to $<1 \mathrm{ng} / \mathrm{ml}$ in estrus, progressively increased from 2 to $<4 \mathrm{ng} / \mathrm{ml}$ in metaestrus and maintained $\geq 4 \mathrm{ng} / \mathrm{ml}$ in diestrus periods according to previously described study [11] [12]. Total of 700 blood samples were collected during three consecutive estrus cycle of 10 animals. Samples were centrifuged and serum was preserved at $-20^{\circ} \mathrm{C}$ freezer for ELISA assay. Optical density (OD) derived from ELISA reader under wavelength of $340-850 \mathrm{~nm}$ were converted to concentrations using Microsoft excel. All data collected from RCC heifers and cows were analyzed by the Microsoft excel.

\section{Results}

\subsection{Measurement of Corpus Luteum (CL) Growth and Regression}

Through daily ultrasound examinations, it was observed that the maximum luleal diameter was $17.61 \pm 0.67 \mathrm{~mm}$ for RCC cows and $16.67 \pm 1.32 \mathrm{~mm}$ for heifers (Figure 1 and Figure 2). Luteal regression took place at $15.00 \pm 1.50$ and 


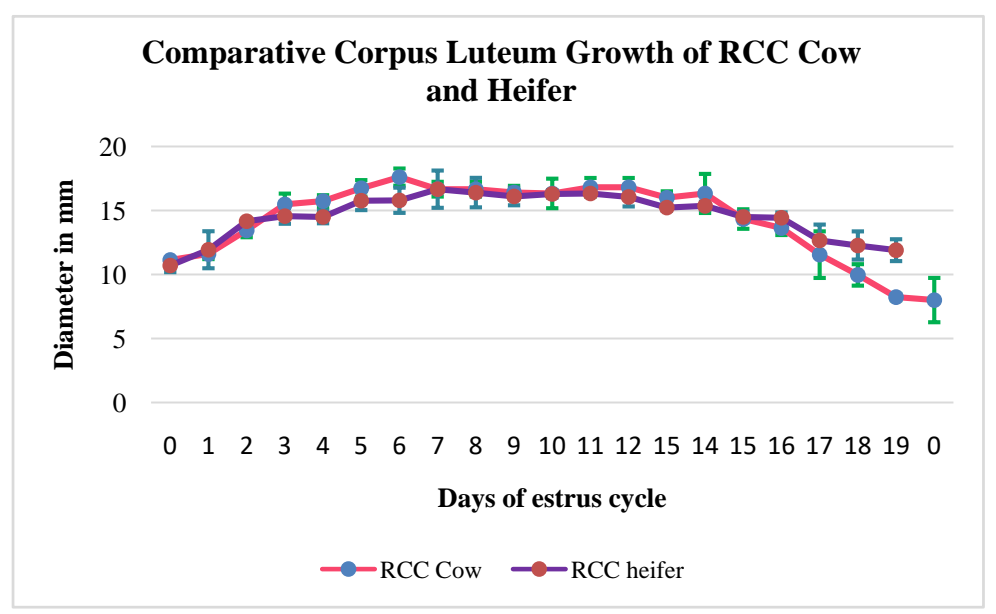

Figure 1. Corpus luteum growth and regression curve of RCC cows and RCC heifers (Mean \pm SD). Here Day 0 means day of estrus.
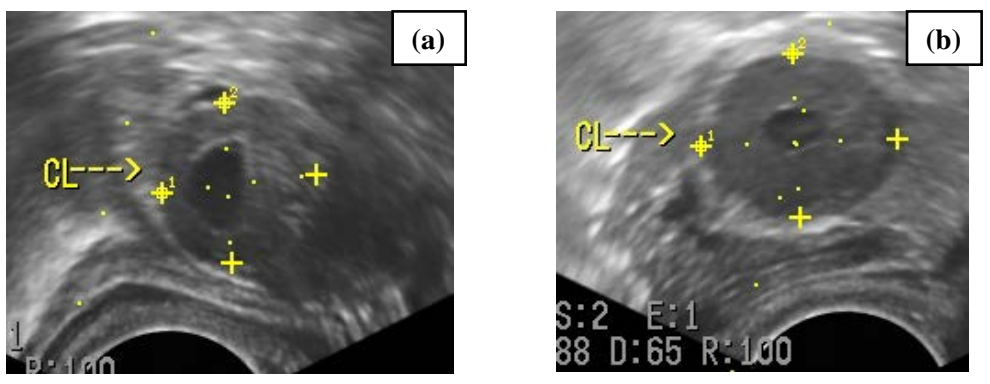

Figure 2. Observation of growth of Corpus luteum (CL) of RCC heifers. (a) $\mathrm{CL}$ of heifer (day-14, diameter-18.1 mm). (b) CL of heifer (day-13, diameter-19.1 mm).

$14.00 \pm 1.50$ days of the estrus cycle for RCC cows and RCC heifers, respectively. No significant differences $(p>0.05)$ were observed between the groups for these variables. Growth curve of CL for both RCC cows and heifers were almost similar (Figure 1).

\subsection{Determination of the Number of Follicle and Length of the Estrus Cycle}

The length of the estrus cycle of RCC cows and heifers were $21.00 \pm 1.50$ and $20.00 \pm 1.10$ days, respectively. The follicular growth pattern occurred in two waves. For all the experimental animals, the emergence of the growth of first follicular wave occurred the day after ovulation, and an average of $8.00 \pm 1.50$ and $5.00 \pm 1.70$ follicles for RCC cows and heifers, respectively were observed on the ultrasound. Follicular deviation in the first wave took place at $4.00 \pm 1.10$ days for RCC cows and $4.00 \pm 1.44$ days for RCC heifers, with a diameter of the dominant follicle of $8.00 \pm 1.70 \mathrm{~mm}$ and $8.00 \pm 1.17 \mathrm{~mm}$, respectively. There were no significant differences between groups for these variables $(p>0.05)$ (Table 1). The second wave of follicular growth began at $12.00 \pm 2.10$ days for RCC cows and $12.00 \pm 1.50$ days for heifers. An average of $6.50 \pm 1.70$ and $6.00 \pm 1.90$ 
Table 1. Duration of the estrous cycle and follicular dynamics of RCC cows and heifers.

\begin{tabular}{lccc}
\hline \multicolumn{1}{c}{ Parameter } & $\begin{array}{c}\text { RCC Cow } \\
\text { (Mean } \pm \text { SD })\end{array}$ & $\begin{array}{c}\text { RCC Heifer } \\
\text { (Mean } \pm \text { SD) }\end{array}$ & p-value \\
\hline Duration of the estrous cycle (days) & $21.00 \pm 1.50$ & $20.00 \pm 1.10$ & 0.055 \\
Number of waves & 2 & 2 & NA \\
Emergence of wave 1 (day of the estrus cycle) & $2.00 \pm 1.50$ & $1.00 \pm 1.84$ & 0.065 \\
Number of follicles in wave 1 & $8.00 \pm 1.50$ & $5.00 \pm 1.70$ & 0.051 \\
Deviation of wave 1 (day of the estrus cycle) & $4.00 \pm 1.10$ & $4.00 \pm 1.44$ & 0.053 \\
Diameter of the deviation of wave 1 (mm) & $8.00 \pm 1.70$ & $8.00 \pm 1.17$ & 0.065 \\
Emergence of wave 2 (day of the estrus cycle) & $12.00 \pm 2.10$ & $12.00 \pm 1.50$ & 0.06 \\
Number of follicles in wave 2 & $6.50 \pm 1.70$ & $6.00 \pm 1.90$ & 0.051 \\
Deviation of wave 2 (day of the estrus cycle) & $14.00 \pm 2.10$ & $15.00 \pm 1.10$ & 0.054 \\
Diameter of the deviation of wave 2 (mm) & $8.00 \pm 1.16$ & $8.80 \pm 0.50$ & 0.062 \\
Diameter of the preovulatory follicle (mm) & $12.00 \pm 1.70$ & $11.00 \pm 1.50$ & 0.066 \\
\hline
\end{tabular}

follicular structures was ultrasonograpically observed for cows and heifers, respectively. The maximum diameter reached by the preovulatory follicle was $12.00 \pm 1.70 \mathrm{~mm}$ for RCC cows and $11.00 \pm 1.50 \mathrm{~mm}$ for heifers. No significant differences were found between the groups for these variables $(p>0.05)$ (Table $1)$.

When comparing the waves of follicular growth among animals, it was found that the interval since the emergence of the wave to the deviation of the dominant follicle was $4.29 \pm 1.89,3.29 \pm 2.17$ days for the first and second wave, respectively; likewise, the number of follicles was $9.11 \pm 2.47$ and $8.18 \pm 1.86$ (Figure 3). Finally, the diameter of the dominant follicle in the deviation was $5.00 \pm 2.00 \mathrm{~mm}$ for wave one, $6.50 \pm 1.00 \mathrm{~mm}$ for wave two. There was no statistical difference $(p>0.05)$ between the waves of follicular growth (Table 2).

Both Red Chittagong Cattle cows and heifers follow two waves of follicular growth. The first dominant follicular diameter of first wave was $11.5 \mathrm{~mm}$ in cows and $10.5 \mathrm{~mm}$ in heifers respectively. Follicular growth follows three steps of growth like increase in diameter (growing phase), remain static (static phase) and decrease in diameter (decreasing phase). This was the first study that characterizes the estrus cycle and ovarian dynamics considering the number of follicular waves in RCC. During each wave, one follicle is selected to become dominant while subordinate follicles in the cohort undergo atresia [12]. The last follicular wave generated in one estrus cycle leads to the preovulatory follicle, and subsequently to ovulation (Figure 4).

The presence or absence of one follicular wave is regulated by secretion of FSH and estrogens. In cattle, genetic predisposition, nutritional status, or uncontrolled environmental conditions may play an important role in regulation of incidence of the two, three, or more follicular waves within one estrus cycle [13] [14]. Previous studies showed that the occurrence of a specified number of 
Table 2. Number of follicles, diameter of deviation and interval of the emergence of deviation in follicular waves of RCC cows and heifers.

\begin{tabular}{lccc}
\hline \multicolumn{1}{c}{ Parameter } & Wave1 & Wave2 & $p$-value \\
\hline Number of follicles & $9.11 \pm 2.47$ & $8.18 \pm 1.86$ & 0.056 \\
Diameter of deviation $(\mathrm{mm})$ & $5.00 \pm 2.00$ & $6.50 \pm 1.00$ & 0.06 \\
Interval of emergence of deviation (days) & $4.29 \pm 1.89$ & $3.29 \pm 2.17$ & 0.055 \\
\hline
\end{tabular}

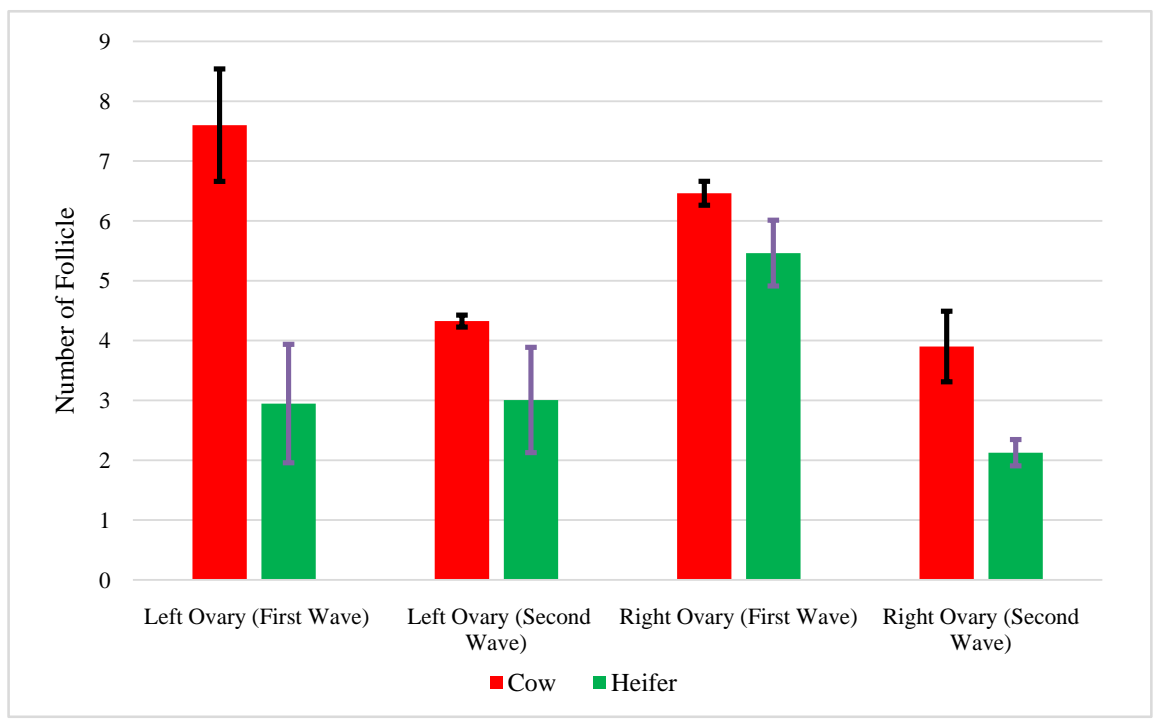

Figure 3. Number of follicles in RCC cows and heifers left and right ovary during estrus cycle (Mean $\pm \mathrm{SD})$.
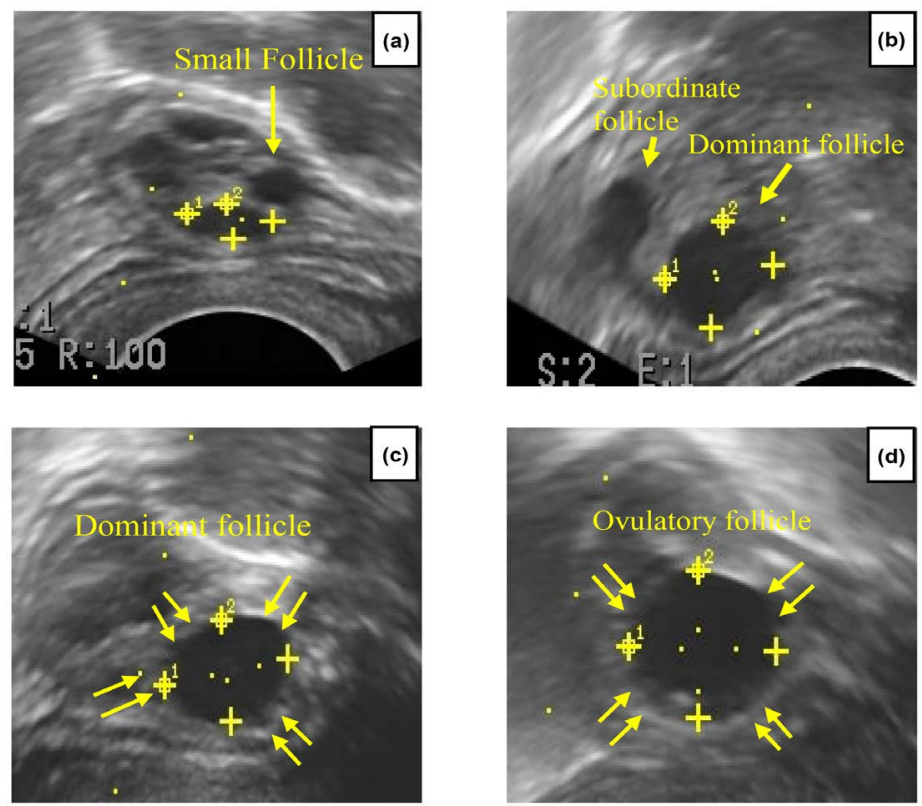

Figure 4. Ultrasonograpic images of ovarian follicles (a). Initiation of a follicular wave. (b). Deviation from subordinate follicle. (c) Dominant follicle of first wave in RCC cows. (d). Ovulatory follicle of the second wave in RCC cows. 
follicular waves in an estrus cycle does not seem to be influenced by breed, age [13], or season of the year. However, an increase in the proportion of the three-wave follicular pattern has been associated to a low plane of nutrition and heat stress [15]. RCC cows and heifers of this study showed estrus cycles with two follicular wave patterns (Figure 5). Therefore, these results suggest that RCC cows and heifers have follicular wave patterns that seem very similar to those observed in heifers of commercial B. taurus breeds. Although the key factors influencing the proportion of two and three wave patterns are not known, there are two general hypothesis that may explain the ovarian events that determine if a third wave arises during an interovulatory interval. A shorter interval between the occurrence of sequential waves could allow more waves to appear, even when the interovulatory interval is kept constant and a longer interovulatory interval could allow the emergence of an additional wave, even when the interval between waves is constant [12].

\subsection{Follicular Dynamics of RCC during Estrus Cycle}

There have been examined 5 RCC cows and 5 heifers with ultrasound machine to observe the follicular growth during estrus cycle of the cows and heifers and recorded the image data daily for three consecutive estrus cycle. The diameter of the follicle was measured daily after storage of the images. There have been found that follicular growth maintained wave like pattern and both RCC cows and heifers showed two waves of growth (Figure 5).

The total number of follicles observed daily was approximately $7 \pm 1.5 \mathrm{in} \mathrm{left}$ ovary and $6 \pm 1$ in right ovary in case of RCC cows and 4 in left ovary and 6 in right ovary in case of RCC heifers (Figure 3). While the follicular wave started, a group of small follicles appeared and gradually they are increased in diameter and become larger. At the initiation of wave, number of follicles remain high, however, later on, the number of follicles decreases, and diameter of the follicles increases. We found that the diameter of ovary increases when the diameter of follicles increases. The number of follicular waves did not affect the maximum size and volume of CL during its development in luteal phase of the cycle, because the maximum diameter of the ovulatory follicle was similar between two follicular waves.

\subsection{Determination of Circulating Blood Concentrations of LH, FSH and $\mathbf{P 4}$}

The mean concentrations of LH calculated from plasma of 3 cycles (5 RCC cows and 5 heifers) basal values are nearly constant. Between day 6 and 10 some smaller but significant elevations of hormonal concentrations can be seen. Concentrations of LH decrease below the calculated mean levels on day 11to day13 and thereafter increase again. A further gradual increase $(P<0.05)$, exceeding the basal levels beginning from day 17 until the preovulatory LH-peak on day 20 can be observed (Figure 6(a)). Immediately before ovulation LH values again 


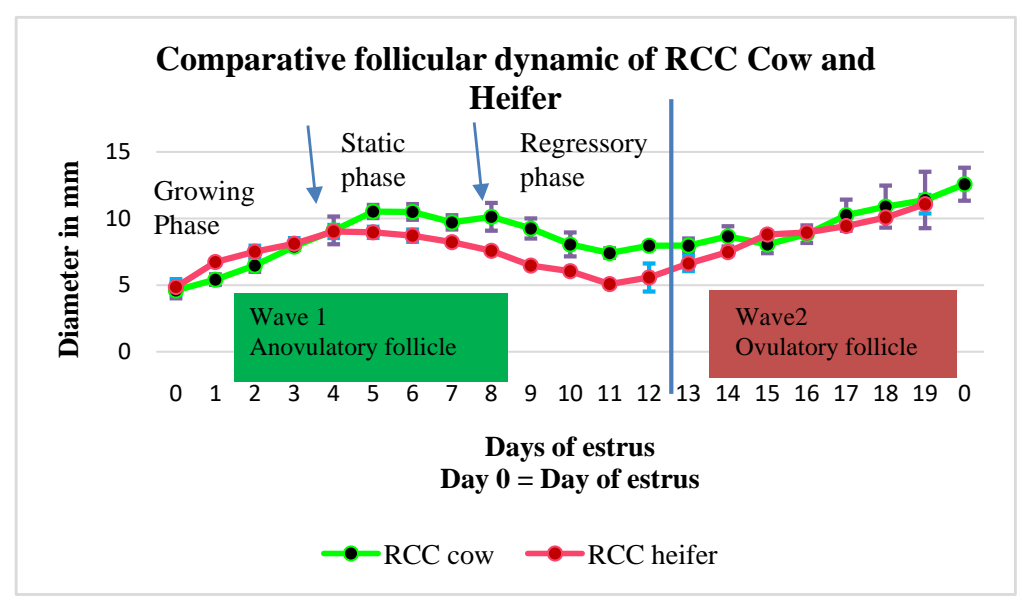

Figure 5. Follicular dynamic of RCC cow and RCC heifer (Mean \pm SD). Here, two blue arrows indicate the initial and end point of static phase and blue line indicates the partition between wavel and wave 2 .

decrease to basal concentrations. The mean plasma levels of FSH ( 2 cycles from 10 animals) followed a constant pattern and FSH-peaks $(P<0.05)$ occurred around days 2, 3, 4 and 13,14, 15 in RCC cows and heifers showing a wavelike pattern (Figure 6(b)). The peaks on days 15 and 16 were distinctly separate. The concentrations determined two days before and three days after ovulation are constantly low between 0.2 and $0.55 \mathrm{ng} / \mathrm{ml}$ plasma in blood serum. From day $4 \mathrm{a}$ gradual increase is observed, and progesterone levels reach a plateau around day 10 after ovulation. Compared to the increase at the beginning of the cycle the decrease at about 5 days before ovulation is more rapid (Figure 6(c)). There is a sharp and significant fall in the progesterone levels on day 17, lasting for about 18 hours.

\section{Discussion}

In general, cattle estrus cycles consist of two or three follicular waves [13]. In this study with RCC through trans-vaginal ultrasonography monitoring of the ovarian follicular dynamics throughout the estrus cycles, all studied RCC cows and heifers showed two follicular waves. Similar findings showed the prevalence of two follicular wave cycles during estrus cycles in Holstein heifers [16]. In contrast, it has been reported that only $20 \%$ of Holstein heifers (B. taurus) [17] or $30.10 \%$ of TNH (B. indicus) [18] had two follicular wave cycles throughout each estrus cycle, and the remainder had three follicular wave cycles.

In this study, it was found that the mean length of the interovulatory intervals in two follicular wave cycles was $20.44 \pm 0.13$ days in RCC heifers and $21 \pm 1.5$ days in RCC cows. The emergence of the first and second follicular waves in two follicular wave cycles of RCC (Day $1.53 \pm 0.17$ and Day 11.02 \pm 0.2 ) occurred later when compared with those of Bahaman heifers ( Day $0.2 \pm 0.1$ and Day $10.0 \pm 0.4)$. However, the RCC are similar in regard to the first and second follicular waves in the two wave cycles of Nelore cattle (Day $1.50 \pm 0.15$ and Day 

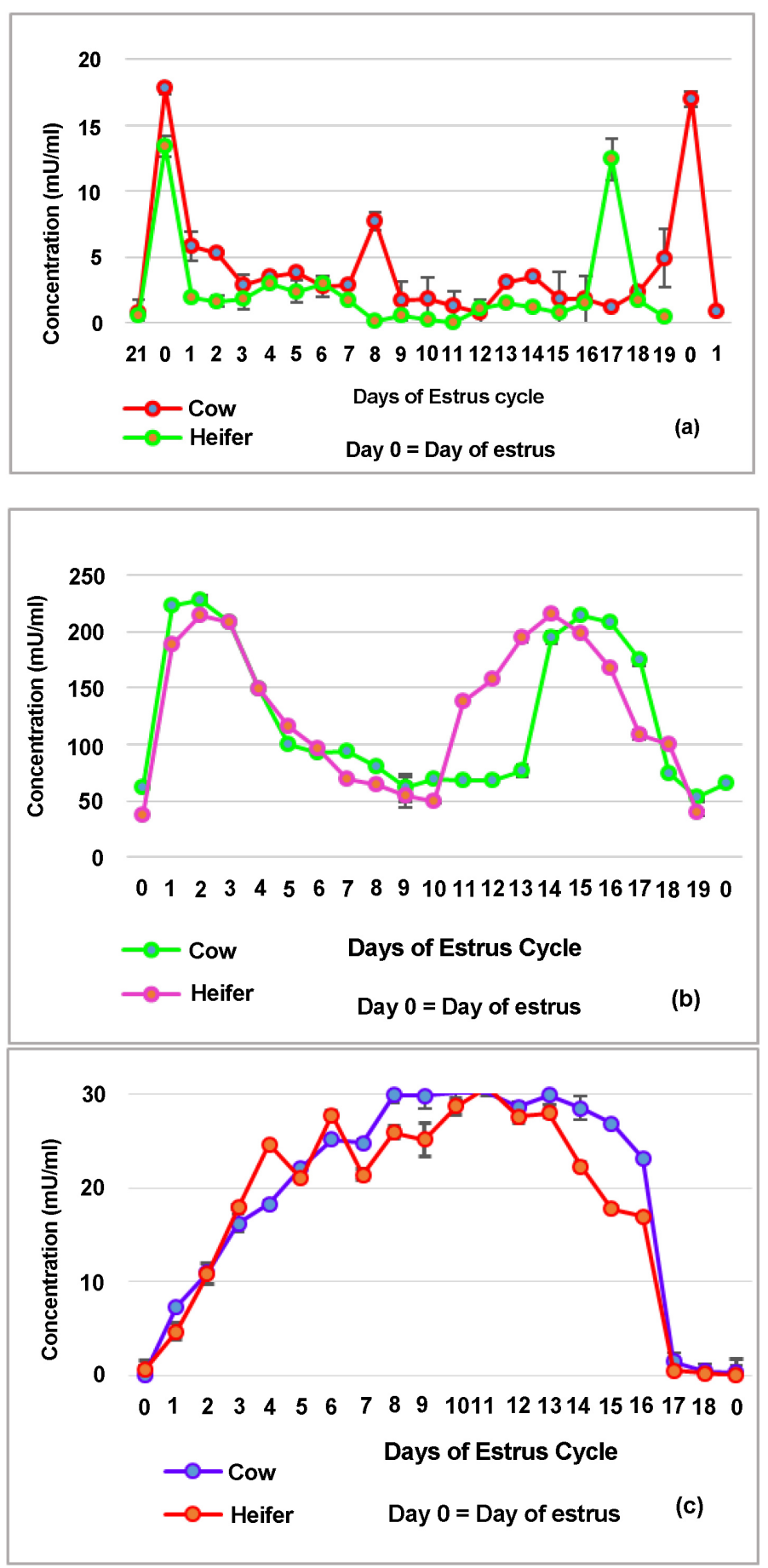

Figure 6. Determination of the circulating blood concentrations of (a) Luteinizing hormone $(\mathrm{LH})(\mathrm{mIU} / \mathrm{ml})$, (b) Follicular Stimulating Hormone (FSH) (mIU/ml); and (c) Progesterone (P4) (ng/ml) during estrus cycle of RCC cows and heifers (Mean $\pm \mathrm{SD}$ ).

$12.0 \pm 0.91$ ) [9]. Furthermore, the lengths of the first and second follicular waves in RCC having the two wave cycles $(12.44 \pm 0.08$ and $8.07 \pm 0.06)$ are similar to those reported in Nelore cattle (14.75 \pm 0.70 and $9.05 \pm 0.69)$ [9] and cross between Friesian and Hereford heifers (14.25 \pm 2.86 and $9.0 \pm 1.08)$ [17]. 
The data from the current study show that the first follicular wave lengths in the two follicular wave cycles of RCC tended to be shorter than those of Nelore and cross between Friesian and Hereford heifers. In all two follicular wave cycles of Nelore cattle the ovulatory wave was shorter than that of the first follicular wave, also in this study the ovulatory wave was shorter compared to the first follicular wave. The maximum diameters of dominant follicle (DF), (8 - $9 \mathrm{~mm}) \mathrm{ob}$ served in RCC heifers and $(10-11 \mathrm{~mm})$ in RCC cows which were smaller than those observed in Nelore heifers (10 - $12 \mathrm{~mm}$ ) [9], Holstein heifers (14 - $20 \mathrm{~mm}$ ) [17] and Brahman heifers $13-18 \mathrm{~mm}$ [16]. However, the diameters were similar to the mean sizes of the DF ( $8-9 \mathrm{~mm}$ ) reported for Chinese Yellow Cattle, while the average of maximum diameters of the $\mathrm{CL}$ for the two follicular wave cycles in RCC (13.55 \pm 0.17 heifers and $15.14 \pm 0.14 \mathrm{~mm}$ cows) were smaller than those observed in Nelore ( 17 - $18 \mathrm{~mm}$ ) [10] and Brahman heifers (18 - $19 \mathrm{~mm})$ [17]. The maximum diameters of CL were smaller than those for Holstein heifers (20 - $25 \mathrm{~mm}$ ) [17]. Thus, the sizes of DF and CL in the ovaries of RCC were smaller than those of $B$. indicus cattle (Nelore and Brahman heifers) and B. taurus (Holstein), but the pattern of growth and turnover of DF were similar among them.

The duration of growth of ovulatory follicle (OF) for two follicular wave cycles of RCC ( $8.24 \pm 0.56$ and $9.51 \pm 0.68$ days $)$ was comparable to that of Nelore cattle having two and three follicular wave cycles $(8.65 \pm 0.73$ and $7.0 \pm 0.51$ days) [9] and Holstein heifers with two and three follicular waves cycles (7.50 \pm 0.19 and $5.90 \pm 0.30$ days) [17] and $10.9 \pm 0.40$ and $6.31 \pm 0.69$ days [19]. However, the growth rates of the OF and other DF were slower in RCC $(\sim 0.80$ $\mathrm{mm} /$ day $)$ than those of Nelore cattle $(\sim 0.92 \mathrm{~mm} /$ day $)$ and European breeds (1.4 - $2.0 \mathrm{~mm} /$ day and $1.8-2.2 \mathrm{~mm} /$ day. Thus, RCC have smaller DF and slower rates of follicular growth than those of Nelore cattle and Holstein heifers. The maximum diameter of the SF in RCC $(\sim 4.50-6.69 \mathrm{~mm})$ was smaller than those of Nelore cattle $(\sim 6-7 \mathrm{~mm})$ [9] and Holstein heifers $(6.3 \pm 0.8 \mathrm{~mm}, 7.4 \pm 0.6$ $\mathrm{mm}$ [19] and $8-9 \mathrm{~mm}$ [13]. In this study, the subordinate follicle (SF) attained about half the size of the DF in RCC. In addition, the mean follicular diameters $(\sim 8-9 \mathrm{~mm})$ of RCC as determined by ultrasonography of the ovaries were similar to those of Chinese Yellow Cattle $(\sim 9 \mathrm{~mm})$. In contrast, the mean follicular diameter was smaller than those reported for Nelore cows and heifers $(\sim 22$ $\mathrm{mm})$, and slightly smaller than that reported for European cattle $(\sim 25 \mathrm{~mm})$. Other reports, based on ovarian weight, body weight or by palpation per rectum suggest that RCC cattle have smaller ovaries than those of $B$. taurus cattle. The number of follicles recruited in the first follicular wave in RCC (5 - 7 follicles) was lower than those in Nelore (14 - 15 follicles) [20], Brahman (13 - 14 follicles) [16] and Holstein heifers (15 - 16 follicles) [21]. Follicle deviation is defined as the beginning of the differential change in growth rate between the largest follicles subsequent to wave emergence and is considered a key component of follicle selection [22]. The follicular deviation after ovulation in RCC observed in the present study ( 1.53 days at emergence of the first follicular wave) was differ- 
ent from those of Nelore heifers [23] and Holstein cows. In Holstein heifers, follicular deviation occurs between 2.2 and 2.8 days after ovulation or wave emergence. Since emergence of the first follicular wave does not usually occur until 24 $\mathrm{h}$ after ovulation in RCC, therefore, follicular deviation seems to occur earlier after wave emergence in TNH than Nelore and Holstein females. Moreover, similar results have been reported in Holstein heifers where there are intervals of 9 days between waves in two follicular wave cycles and approximately 7 days between waves in three follicular wave cycles [19].

Concentrations of FSH during the estrus cycle in two follicular wave cycles of RCC heifers and cows were $0.96-2.25 \mathrm{mIU} / \mathrm{mL}$ and $1.13-2.32 \mathrm{mIU} / \mathrm{ml}$ respectively. Moreover, the concentration of FSH in the RCC cows and heifers were almost similar and no significant difference was observed. In RCC cows, slightly greater FSH concentrations have also been found. In the present study, the FSH concentrations decreased from 48 to $24 \mathrm{~h}$ before deviation and remained at basal levels for 24 to $96 \mathrm{~h}$ after deviation and this corresponds well to the B. taurus females. In the present study, $\mathrm{P}_{4}$ concentration progressively increased from $<1$ $\mathrm{ng} / \mathrm{ml}$ at days $1-2$ post-ovulation to approximately $\geq 27 \mathrm{ng} / \mathrm{ml}$ at days $4-6$, consequently follicular deviation becomes started in the first follicular wave. Interestingly with the continuous maintenance of the animals, $\mathrm{P}_{4}$ concentration is declined to $<1 \mathrm{ng} / \mathrm{ml}$ duringthe ovulation time. The roles of $\mathrm{P}_{4}$ in follicular wave development were unclear, but it has been reported that $\mathrm{P}_{4}$ could have a direct effect on follicle development or could affect LH secretion [14], while the relationship of $\mathrm{P}_{4}$ with follicular deviation may be merely a temporal association that does not reflect a cause-effect relationship [20]. Furthermore, the dynamics of follicular deviation was not affected by circulating $\mathrm{P}_{4}$ concentrations [24].

\section{Conclusion}

RCC is the most promising indigenous cattle variety in Bangladesh having many superior characteristics over others native cattle. However, there is no study to date on follicular development in RCC. The follicular dynamics in RCC heifers and cows during natural estrus cycle were studied in this study with a special link up to follicular waves and the circulating concentration of $\mathrm{P}_{4}, \mathrm{LH}$ and FSH. The ovarian follicular dynamics pattern in RCC cows and heifers followed two wave patterns. Moreover, the number of follicles recruited per wave was dissimilar between RCC cows and heifers, the emergence of each follicular wave in RCC heifers was later, and length of the interovulatory intervals was shorter when compared with RCC cows. $\mathrm{P}_{4}, \mathrm{FSH}$ and $\mathrm{LH}$ concentrations determined by ELISA associated with follicular size have an important role in controlling follicular development and determining whether an estrus cycle will have two or three follicular wave cycles. These studies will help us to understand the mechanisms regulating the development of follicular waves during the estrus cycle as well as follicular development and ovulations. Documentation of a wave phenomenon of ovarian follicular development in RCC will provide a new model for folliculogenesis during the others native cattle estrus cycle. It is anticipated that 
the knowledge of follicular waves during the estrus cycle will have profound implications for infertility diagnoses and treatment in bovine species such as repeat breeding.

\section{Funding}

This research project was supported by the RCC Improvement and Conservation project (Second Phase) of Bangladesh Livestock Research Institute (BLRI), Savar, Dhaka-1341, Bangladesh.

\section{Conflicts of Interest}

We declare no conflict of interest.

\section{References}

[1] Bhuiyan, A.K.F.H., Hossain, M.M. and Deb, G.K. (2007) Indigenous Cattle Genetic Resources of Bangladesh and a Way forward to Their Development. Bangladesh Journal of Progressive Science and Technology, 5, 105-112.

[2] Pierson, R.A. and Ginther, O.J. (1988) Ultrasonic Imaging of the Ovaries and Uterus in Cattle. Theriogenology, 29, 21-37. https://doi.org/10.1016/0093-691X(88)90029-5

[3] Sirois, J. and Fortune, J.E. (1988) Ovarian Follicular Dynamics during the Estrous Cycle in Heifers Monitored by Real-Time UItrasonograph. Biology of Reproduction, 39, 308-317. https://doi.org/10.1095/biolreprod39.2.308

[4] Gastal, E.L., Gastal, M.O. and Ginther, O.J. (2006) Relationships of Changes in B-Mode Echo Texture and Colour-Doppler Signals in the Wall of the Preovulatory Follicle to Changes in Systemic Oestradiol Concentrations and the Effects of $\mathrm{Hu}$ man Chorionic Gonadotrophin in Mares. Reproduction, 131, 699-709.

https://doi.org/10.1530/rep.1.01011

[5] Gimenes, L.U., Carvalho, N.A.T., Sá Filho, M.F., Vannucci, F.S., Torres-Júnior, J.R.S., Ayres, H., Ferreira, R.M., Trinca, L.A., Sartorelli, E.S., Barros, C.M. and Beltran, M.P. (2011) Ultrasonographic and Endocrine Aspects of Follicle Deviation, and Acquisition of Ovulatory Capacity in Buffalo (Bubalus bubalis) Heifers. Animal Reproduction Science, 123, 175-179. https://doi.org/10.1016/j.anireprosci.2010.12.004

[6] Kruip, T.A., Moor, R.M. and Green, D. (1984) Intraovarian Control of Folliculogenesis: Limits to Superovulation? Theriogenology, 21, 103-116. https://doi.org/10.1016/0093-691X(84)90310-8

[7] Monniaux, D., Mariana, J.C. and Gibson, W.R. (1984) Action of PMSG on Follicular Populations in the Heifer. Reproduction, 70, 243-253. https://doi.org/10.1530/jrf.0.0700243

[8] Ginther, O.J., Jacob, J.C., Gastal, M.O., Gastal, E.L. and Beg, M.A. (2008) Follicle and Systemic Hormone Interrelationships during Spontaneous and Ablation-Induced Ovulatory Waves in Mares. Animal Reproduction Science, 106, 181-187. https://doi.org/10.1016/j.anireprosci.2007.12.018

[9] Figueiredo, R.A., Barros, C.M., Pinheiro, O.L. and Soler, J.M.P. (1997) Ovarian Follicular Dynamics in Nelore Breed (Bos indicus) Cattle. Theriogenology, 47, 1489-1505. https://doi.org/10.1016/S0093-691X(97)00156-8

[10] Vasconcelos, J.L.M., Sartori, R., Oliveira, H.N., Guenther, J.G. and Wiltbank, M.C. 
(2001) Reduction in Size of the Ovulatory Follicle Reduces Subsequent Luteal Size and Pregnancy Rate. Theriogenology, 56, 307-314.

https://doi.org/10.1016/S0093-691X(01)00565-9

[11] Ginther, O.J., Kastelic, J.P. and Knopf, L. (1989) Composition and Characteristics of Follicular Waves during the Bovine Estrous Cycle. Animal Reproduction Science, 20, 187-200. https://doi.org/10.1016/0378-4320(89)90084-5

[12] Ginther, O.J., Knopf, L. and Kastelic, J.P. (1989) Ovarian Follicular Dynamics in Heifers during Early Pregnancy. Biology of Reproduction, 41, 247-254. https://doi.org/10.1095/biolreprod41.2.247

[13] Adams, G.P., Jaiswal, R., Singh, J. and Malhi, P. (2008) Progress in Understanding Ovarian Follicular Dynamics in Cattle. Theriogenology, 69, 72-80. https://doi.org/10.1016/j.theriogenology.2007.09.026

[14] Noseir, W.M. (2003) Ovarian Follicular Activity and Hormonal Profile during Estrous Cycle in Cows: The Development of 2 versus 3 Waves. Reproductive Biology and Endocrinology, 1, 50.

[15] Wolfenson, D., Thatcher, W.W., Badinga, L., Savi, J.D., Meidan, R., Lew, B.J., Braw-Tal, R. and Berman, A. (1995) Effect of Heat Stress on Follicular Development during the Estrous Cycle in Lactating Dairy Cattle. Biology of Reproduction, 52, 1106-1113. https://doi.org/10.1095/biolreprod52.5.1106

[16] Rhodes, F.M., De'Ath, G. and Entwistle, K.W. (1995) Animal and Temporal Effects on Ovarian Follicular Dynamics in Brahman Heifers. Animal Reproduction Science, 38, 265-277. https://doi.org/10.1016/0378-4320(94)01375-V

[17] Savio, J.D., Boland, M.P. and Roche, J.F. (1990) Development of Dominant Follicles and Length of Ovarian Cycles in Post-Partum Dairy Cows. Reproduction, 88, 581-591. https://doi.org/10.1530/jrf.0.0880581

[18] Sakhong, D., Vongpralub, T., Katawatin, S. and Sirisathien, S. (2011) Ovarian Follicular Patterns and Hormone Profile in Thai Native Cattle (Bos indicus). The Thai Journal of Veterinary Medicine, 41, 439-448.

[19] Fortune, J.E. (1994) Ovarian Follicular Growth and Development in Mammals. Biology of Reproduction, 50, 225-232. https://doi.org/10.1095/biolreprod50.2.225

[20] Castilho, C., Garcia, J.M., Renesto, A., Nogueira, G.P. and Brito, L.F. (2007) Follicular Dynamics and Plasma FSH and Progesterone Concentrations during Follicular Deviation in the First Post-Ovulatory Wave in Nelore (Bos indicus) Heifers. Animal Reproduction Science, 98, 189-196. https://doi.org/10.1016/j.anireprosci.2006.03.008

[21] Bo, G.A., Adams, G.P., Caccia, M., Martinez, M., Pierson, R.A. and Mapletoft, R.J. (1995) Ovarian Follicular Wave Emergence after Treatment with Progestogen and Estradiol in Cattle. Animal Reproduction Science, 39, 193-204. https://doi.org/10.1016/0378-4320(95)01389-H

[22] Sartori, R., Fricke, P.M., Ferreira, J.C., Ginther, O.J. and Wiltbank, M.C. (2001) Follicular Deviation and Acquisition of Ovulatory Capacity in Bovine Follicles. Biology of Reproduction, 65, 1403-1409. https://doi.org/10.1095/biolreprod65.5.1403

[23] Sartorelli, E.S., Carvalho, L.M., Bergfelt, D.R., Ginther, O.J. and Barros, C.M. (2005) Morphological Characterization of Follicle Deviation in Nelore (Bos indicus) Heifers and Cows. Theriogenology, 63, 2382-2394. https://doi.org/10.1016/j.theriogenology.2004.08.017

[24] Beg, M.A., Meira, C., Bergfelt, D.R. and Ginther, O.J. (2003) Role of Oestradiol in Growth of Follicles and Follicle Deviation in Heifers. Reproduction, 125, 847-854. https://doi.org/10.1530/rep.0.1250847 